\title{
AWARENESS OF PROBLEMS DUE TO MENSTRUATION IN SCHOOL GOING GIRLS- HYDERABAD SINDH
}

\author{
Shama Nawaz ${ }^{1}$ Rozina Khalid'and Nandlal Serani ${ }^{2}$ \\ ${ }^{1}$ Health Services Academy Islamabad \\ ${ }^{2}$ Liaquat University of Medical and Health Sciences Jamshoro \\ Correspondence: Shama Nawaz. Email: msphs14shama@hsa.edu.pk
}

\begin{abstract}
Background: Menstruation is a major stage of puberty in girls, one of the many physical signs that a girl is turning into a woman. Women having better knowledge about menstrual hygiene and safe practices are less vulnerable to RTI and its consequences. Therefore, increased knowledge about menstruation right from childhood may escalate practices and may help in mitigating the suffering of millions of women. This study carried out to gather information regarding menstruation, hygiene related practices and its related problems among adolescent girls along with to review perceptions, belief and expectations regarding menstruation among adolescent girls.

Methods: A Cross-sectional study was conducted, 314 girls of 12 to 15 years were identified as sample from 5 girls high schools. Pre tested pre designed questionnaire was used. Data were analyzed by using SPSS (Version 22). Descriptive statistics used to determine mean age of the subjects, age at menarche, frequency of menstrual disorders and activities affected by this condition.

Results: Mean age of the sample was 14.25 years, with mean age of menarche 12.6 years. $52.6 \%$ of the girls belong to the mothers who are illiterate. $50.7 \%$ girls were aware of menstruation before menarche with major source of the information is mother (71.2\%). 97.8\% perceived menstruation as a normal process. $55.1 \%$ participants said they missed their school during menstruation. 96.4\% experiencing pain and cloth was most common source of absorbent used by $60.2 \%$.

Conclusion: Mothers are the main source of information for young girls. Major reason for absenteeism from school was fear of stain, it has been suggested through cleanliness available for changing absorbent (pad/cloth) the ratio of absenteeism can be reduce.
\end{abstract}

Keywords: menstruation, hygiene, puberty, perception

\section{Introduction:}

Childhood to adulthood transition takes place during adolescence period which is characterized by major biological changes like physical growth, sexual maturation, and psycho-social development. As per World Health Organization (WHO), adolescence is the age group of 10-19 years and currently makes up $18 \%$ of the world's population. It is marked by enhanced food requirement, increased basal metabolic and biochemical activities, endogenous processes like hormonal secretions with their influence on the various organ systems of which menarche is the most important event in case of adolescent girls that requires specific and special attention. It marks the beginning of woman's menstrual and reproductive life which occurs between 11 and 15 years with a mean of 13 years. It is qualitative event of major significance in woman's life, denoting the achievement of major functional state. Even though menstruation is a natural process, it is linked with several misconceptions, complex societal stigmas, fears, and malpractices which may result in undesirable health outcomes.

In one study it was viewed as an event that happens to girls during puberty occurring monthly where the body gets rid of spoiled blood. However, girls who had information about menstruation before menarche had a positive attitude.

Poor hygiene during menstruation has been associated with serious ill-health, including reproductive tract and urinary tract infections. During menstruation, girls experience different feelings including fear, shame and guilt because of lack of prior information about menstruation. A study done among Nigerian secondary school girls revealed that adolescent girls gave different meanings to menstruation and perceived it as physiological process, as an assurance of fecundity, and as a release of bad blood.

Repeated use of unclean cloth, and improperly dried cloth, before its reuse results in harboring of microorganisms resulting in the spread of vaginal infections among adolescent girls (Paul 2007).

During menstruation, girls experience different 
feelings including fear, shame and guilt because of lack of prior information about menstruation.

Women having better knowledge about menstrual hygiene and safe practices are less vulnerable to RTI and its consequences. Therefore, increased knowledge about menstruation right from childhood may escalate practices and may help in mitigating the suffering of millions of women. With this in mind, the present study was carried out to gather information regarding menstruation, hygiene related practices of menstruation, and its related problems among adolescent girls along with to review perceptions, belief and expectations regarding menstruation among adolescent girls.

\section{Methodology}

Cross sectional study was conducted in girl's schools of taluka Qasimabad - Hyderabad District from Oct 2015 to Dec 2015. The data for eligible schools was obtained from the District Education Office, Hyderabad. Total registered girls of $12-15$ years in high schools of taluka Qasimabad was 349. Absent 13, parents of 22 girls did not give consent. 40 girls were excluded as they had not experience menstruation yet. Therefore 274 girls were identified as sample and interviewed through pre designed selfadministered questionnaire after taking ethical approval from HSA, D.E.O Hyderabad, head of the schools and girl's parents. For the ease of participants, main tool (questionnaire) was translated into local language (Sindhi). Tool was pre tested and necessary changes were made.

The data were analyzed by using SPSS version 22.0.

\section{Results:}

In this survey the total sample was based on the female sample size falling in different ages.

Figure 1. Percentage of respondents

Please caption at the bottom of the figures

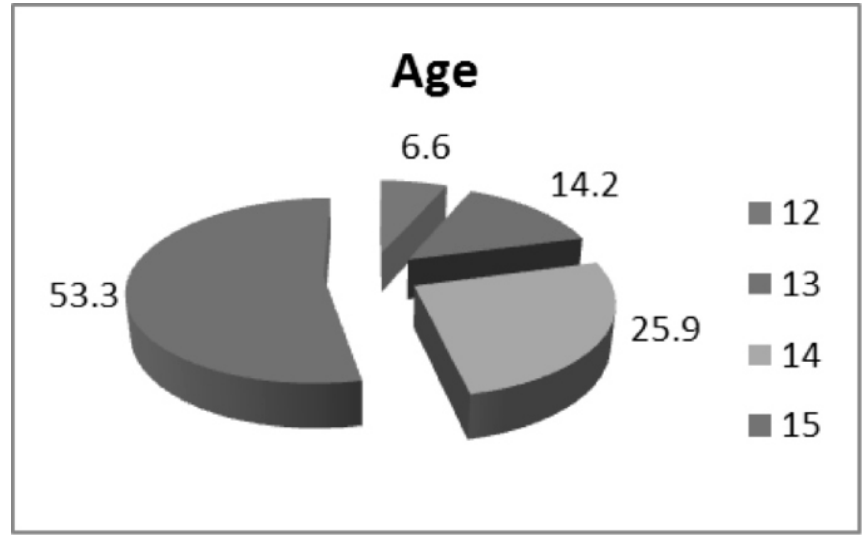

The survey covered total 274 girls of $12-15$ years age. Mean age of the sample was 14.25 . out of 274 girls $18(6.6 \%)$ were of 12 years old, $39(14.2 \%)$ were of 13 years old, $71(25.9 \%)$ were of 14 years old, and $146(53.3 \%)$ were of 15 years old.

Half of the girls out of 274 belongs to illiterate mothers i-e $144(52.6 \%)$.while $44(16.1 \%)$ with primary,
23(8.4\%) with middle, 33(12\%) with matric and 15 girls i-e $5.5 \%$ belongs to mothers having intermediate education. Only mother of 6 and 7 girls have graduation and post-graduation degree respectively. And 2 girls were not aware of their mother's education level

Figure 2. Percent distribution of mothers' education

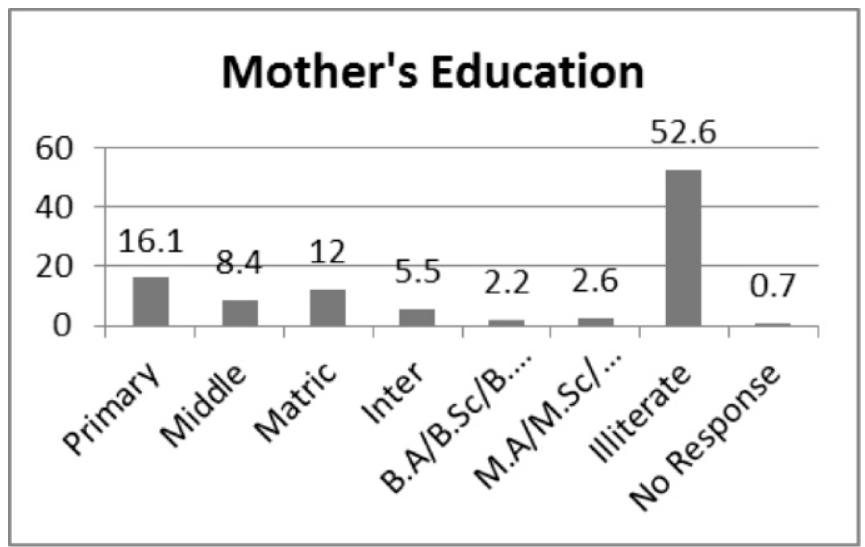

Mean age of menarche among the sample was identified as 12.6 years. While most of the girls experience their first menstruation between the ages of 12 to 13 years. Only 3 experience it at the age of 10 years and 7 at 15 years of age.

Table-1: First Menstruation

\begin{tabular}{|c|c|l|}
\hline $\begin{array}{l}\text { First } \\
\text { Menstruation } \\
\text { (Age) }\end{array}$ & Number & $\begin{array}{c}\text { Percentage } \\
\text { (\%) }\end{array}$ \\
\hline 10.00 & 3 & 1.1 \\
\hline 11.00 & 21 & 7.7 \\
\hline 12.00 & 101 & 36.9 \\
\hline 13.00 & 110 & 40.1 \\
\hline 14.00 & 32 & 11.7 \\
\hline 15.00 & 7 & 2.6 \\
\hline Total & $\mathbf{2 7 4}$ & $\mathbf{1 0 0 . 0}$ \\
\hline
\end{tabular}

Hundred thirty nine (139) girls i-e $50.7 \%$ were aware of menstruation before they had started menstruating while 135 girls i-e $49.3 \%$ had no prior knowledge about it.

Chart-3 Aware of Menstruation

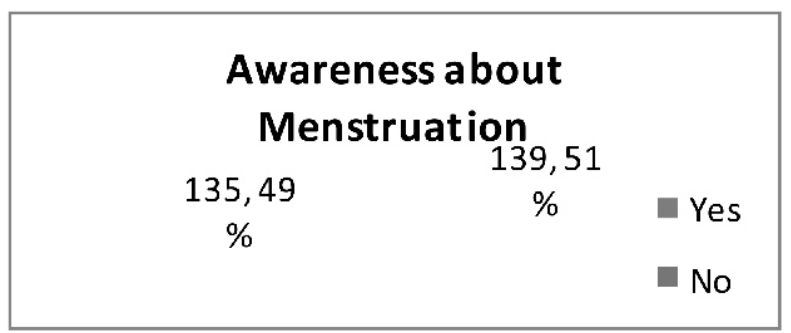


Figure 4: Source of Information

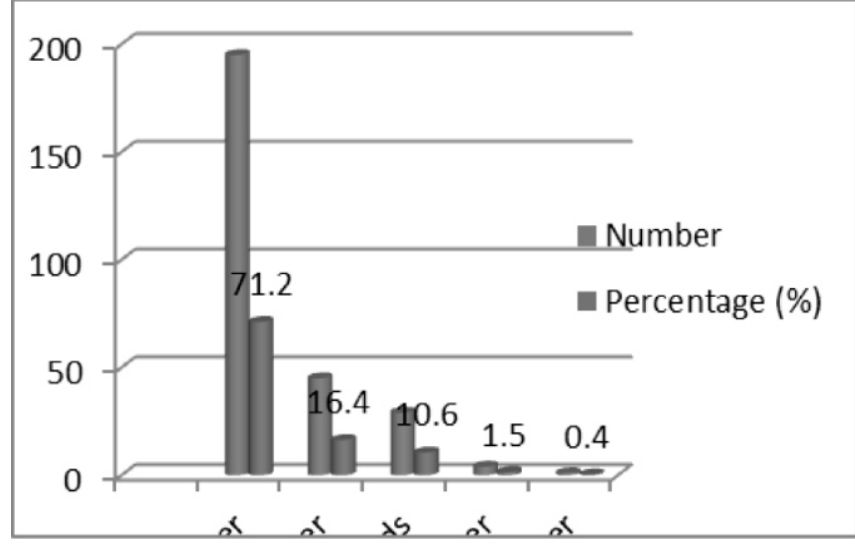

Out of 274, 216 (78.8\%) participant responded that during their periods their routine activities are affected and they did not perform as they perform during other days of month, while $53(19.3 \%)$ said menstruation does not affect their routine activities. 5 participants did not give any response.

Table - 2 Routine Activities

\begin{tabular}{|l|c|c|}
\hline $\begin{array}{l}\text { Routine } \\
\text { Activities }\end{array}$ & Number & $\begin{array}{c}\text { Percentage } \\
\text { (\%) }\end{array}$ \\
\hline Yes & 216 & 78.8 \\
\hline No & 53 & 19.3 \\
\hline $\begin{array}{l}\text { No } \\
\text { Response }\end{array}$ & 5 & 1.8 \\
\hline Total & $\mathbf{2 7 4}$ & $\mathbf{1 0 0 . 0}$ \\
\hline
\end{tabular}

$151(55.1 \%)$ out of 274 participant said yes they missed their school while $121(44.2 \%)$ said no. 2 $(0.7 \%)$ participants did not give any response.

\section{Chart - 5 absent from School}

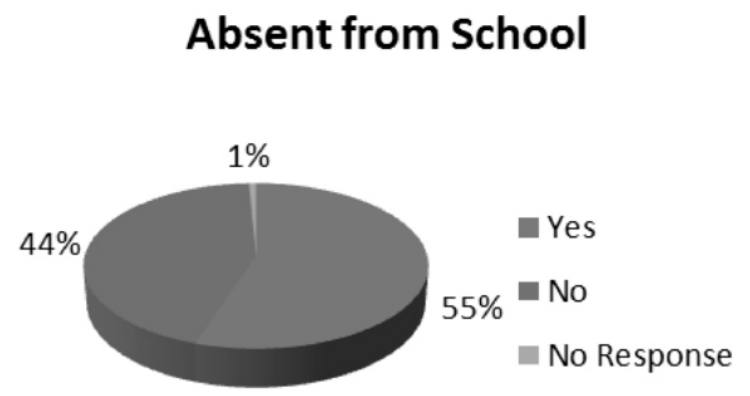

Out of 274, 151 participants who were asked the reasons of their absenteeism; majority that is 76
(50.4\%) responded that due to fear of stain on their cloth they avoid to go to school during the days of menstruation. 49 (32.4\%) said due to menstrual pain, $16(10.6 \%)$ said due to heavy bleeding, $4(2.6 \%)$ said due to lack of cleanliness of toilets in school, $3(2 \%)$ said due to lack of water in school toilets while $3(2 \%)$ did not give any response.

$86(31.4 \%)$ experience nausea, 34 (12.4\%) vomiting, $105(38.3 \%)$ headache, $16(5.8 \%)$ participant said they fainted sometime during their periods. $21(7.7 \%)$ responded they experience symptoms other than these while $12(4.4 \%)$ participants did not give any response.

Table - 3 Associated Symptoms

\begin{tabular}{|l|c|c|}
\hline $\begin{array}{l}\text { Associated } \\
\text { Symptoms }\end{array}$ & Number & $\begin{array}{c}\text { Percentage } \\
(\mathbf{\%})\end{array}$ \\
\hline Nausea & 86 & 31.4 \\
\hline Vomiting & 34 & 12.4 \\
\hline Headache & 105 & 38.3 \\
\hline Fainting & 16 & 5.8 \\
\hline Other & 21 & 7.7 \\
\hline No response & 12 & 4.4 \\
\hline Total & $\mathbf{2 7 4}$ & $\mathbf{1 0 0 . 0}$ \\
\hline
\end{tabular}

Different females use different sort of absorbent according to their culture and family background. Majority 165 (60.2\%) participant during this survey are using cloth while sanitary pad is second most common type of absorbent used by 102 (37.2\%) participant. Other rare type used is cotton by $4(1.4 \%)$, 1 participant was using some other type while 2 $(0.7 \%)$ did not give any response.

\section{Figure 6 Absorbent Use}

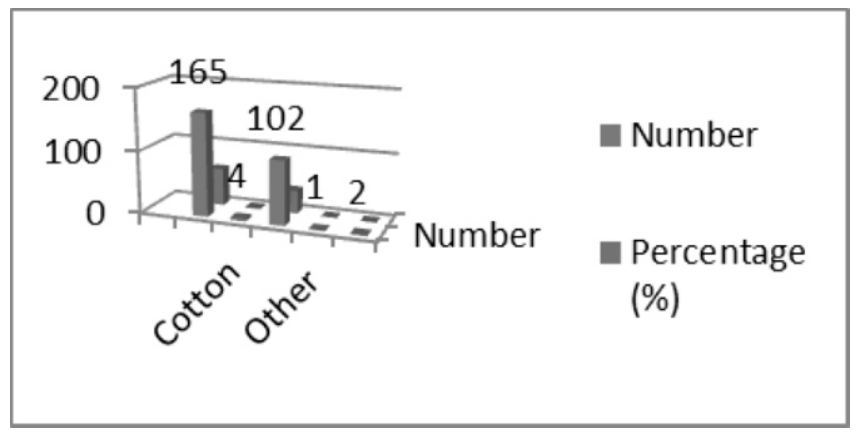

According to literature using home remedies to relieve pain is a very common practice, but when participant were asked about home remedies only $36(13.1 \%)$ said they have used home remedies and majority 200 $(73 \%)$ said they never used any home remedy to relieve the pain and $38(13.9 \%)$ did not give any response. 
Table-4: Home Remedies

\begin{tabular}{|l|c|c|}
\hline $\begin{array}{l}\text { Home } \\
\text { Remedies }\end{array}$ & Number & $\begin{array}{c}\text { Percentage } \\
(\mathbf{\%})\end{array}$ \\
\hline Yes & 36 & 13.1 \\
\hline No & 200 & 73.0 \\
\hline $\begin{array}{l}\text { No } \\
\text { Response }\end{array}$ & 38 & 13.9 \\
\hline Total & $\mathbf{2 7 4}$ & $\mathbf{1 0 0 . 0}$ \\
\hline
\end{tabular}

\section{Discussion}

The onset of menstruation is a life changing incident for girls across the world. The present survey was conducted with the aim to assess the prevailing knowledge of young school going girls about menstruation related problems and their management. Young people in Pakistan have very limited knowledge about sexual and reproductive health, and majority of them have different misconceptions.

The level of educational of both parents and the sources of information about menstruation significantly associated with pre-menstrual training. Girls whose parents especially mothers are educated and those whose mothers are their main source of information are better aware of the problems associated with menstruation and menstrual hygiene. Mother is the first to whom children start to learn on their early stage, especially girls. If the mother is educated she can train their children much better especially regarding hygiene. So the level of education of mother is very important for girls in order to maintain their menstrual hygiene. Our studies reveals that $52.6 \%$ girls belong to illiterate mother while others belong to educated mothers.

Though it is desirable to have school teacher or health worker to be the first source of information ensuring that right knowledge has been imparted, it was seen during this study that major source of information in the study was mother $(71.2 \%)$ followed by sister $16.4 \%$ and friends (10.6\%).

This survey also find that 139 girls i-e $50.7 \%$ were already aware of menstruation before they had started menstruating through different source of information which is almost similar with observations i-e $45.5 \%$ made by a study conducted in East Delhi on awareness and practices of menstruation and pubertal changes amongst unmarried female adolescents, while other study reported lower levels of awareness (28\%). These variations can be due to the different regions surveyed and differences in the socioeconomic status and literacy status of the study subjects in the respective studies.

Interestingly, the source of information for about 195 $(71.2 \%)$ girls was mother who first told them about menstrual periods and menstruation in the survey. This shows healthy sign of the society where the relation of mother and daughter are more comfortable. As we earlier discussed that most of the mothers have no schooling in their life so it can be assume that they have limited knowledge and information about the menstruation.

There are different perceptions of different people about menstruation. Faulty perceptions or misconceptions on menstruation and menstrual cycle will lead to faulty menstrual practices. Either of these may engender reproductive health problems.

$97.8 \%$ subjects included in this study perceived menstruation as a normal process while only $2.2 \%$ thinks it's not normal, and perceived it something else. Whereas one of the study conducted in turkey on perception about menarche and menstruation reveals that $64.2 \%$ females perceived their menarche as an unfavorable experience. $48.8 \%$ of them felt they had to keep their menstruation as a secret, and $2.2 \%$ believed that menstruating was a curse given by God. Taking regular bath and keep one's own self clean is important hygienically. Majority of sample were taking bath during their menstrual period while observation of similar type of study conducted in urban Karachi reported that nearly $50 \%$ of the participants reported that they did not take baths during menstruation.

The reason for not taking bath was revealed during the survey that few participants were restricted by their mother from taking bath while others herself perceived that it is harmful for their health if they take bath during menstruation, these findings are similar which were observed during FGD conducted in Karachi that taking bath during menstruation was harmful to their health, as it actually causes fevers, backaches, an increase in menstrual pain and abdominal pains, while one study reveals entirely opposite finding that only $1.6 \%$ avoided bathing during menstruation.

It has been noted from the survey finding that big junk a major portion of $78.8 \%$ participant responded that during their periods their routine activities are affected and they did not perform as they perform during other days of month and it is also observed by other study that daily routine of $60 \%$ girls was affected, they missed social activities and commitments, disturbed sleep and decreased appetite. $17.24 \%$ were fail to attained class and $25 \%$ had to abstain from work.

It is also revealed from the survey that menstruation and related problems can affect school attendance and performance of young girls. This is why participants were asked during survey that did they ever missed their school due to menstruation or its related problems. $55.1 \%$ of participant said yes they missed their school due to menstruation while $44.2 \%$ said no.

Moreover, when they asked with the option to provide the reason of absent, $50.4 \%$ responded that due to fear of stain on their cloth they avoid to go to school during the days of menstruation. $32.4 \%$ said due to 
dysmenorrhea $10.6 \%$ said due to heavy bleeding, $2.6 \%$ said due to lack of cleanliness of toilets in school. While In the study done by Desalegn Tegabu Zegeye et al, dysmenorrhea was the leading cause of short-term school absenteeism which is about $48.8 \%$ and more female students with moderate to severe dysmenorrhea (68\%), as compared to mild $(43.4 \%)$ were absent from school because of the pain .

It was seen in present study that $60.2 \%$ used cloth as absorbent and $37.20 \%$ used sanitary pads which is similar to the findings of other study that $74.8 \%$ of the girls used homemade sanitary pads, nearly $24 \%$ used ready-made sanitary pads, while $1.5 \%$ used cotton wool []. Whereas in other similar type of study conducted it was found that sanitary pad was used by $73 \%$ girls, Cloth by $22 \%$, other nonspecific absorbents by $5 \%$. The use of cloths was higher which was probably due to the fact that pads were not in the reach or not affordable by majority of respondents as they belong to low socio economic families.

It was observed that the usual practice was to wash cloth with soap and water after use and dry it at some secret place like house corner. To keep the clothes away from curious eyes, they are hidden in some unhygienic places. Privacy for washing, changing or cleaning purpose is something very important for proper menstrual hygiene.

During one of the study $92 \%$ of the girls were restricted from worshipping, $70 \%$ were limited from participating in household activities, and $56 \%$ girls did not eat oily, cold, or spicy foods such as pickles during menstruation []. As compare the restriction revealed during our study were like $62.4 \%$ girls were restricted to perform routine work and $55.1 \%$ were restricted to attend the school, possibly due to ignorance and false perceptions regarding menstruation. The reason for this may not be due to lack of prior knowledge regarding menstruation, but may be due to inadequate or wrong knowledge and low levels of education especially among the mothers.

Type of remedies used by participants were observed to be $22.3 \%$ participants was drinking warm milk, $4(11.2 \%)$ were using boil egg, $8.3 \%$ using hot water massages and phakki respectively, $2.8 \%$ were using self-medication and zorr while 14 participants did not give any response.

\section{Conclusion}

Knowledge is an important factor, with adequate menstrual knowledge the girls will be able to cope with the important menstrual health related issues. Mothers are the main source of information for young girls. In any society, education plays a vital and key role for the development of human behavior and to understand the main issues of the society. It has been noted that in current survey though provide the education but still a part of quality education including menstrual and reproductive education is missing. Major reason for absenteeism from school was fear of stain, it has been suggested that make necessary arrangement, including cleanliness available for changing absorbent (pad/cloth) the ratio of absenteeism can be reduce.

\section{Refrences:}

1. http://www.unicef.org/adolescence/files/ sowc_2011_main_report_en_02092011.pdf

2. Abeer E, Houaida H, Wafaa E: Menstrual attitude and knowledge among Egyptian female adolescents. J Am Sci 2012, 8(6):555-565.

3. dasgupta a, sarkar m: menstrual hygiene: how hygienic is the adolescent girl.indian j community med 2008, 33(2):77-80. \&prateek s, saurabh r: a cross sectional study of knowledge and practices about reproductive health among female adolescents in an urban slum of mumbai. j famreprod health 2011, 5(4):117-124

4. Oche M, Umar A, Gana G, Ango J: Menstrual health: the unmet needs of adolescent girls' in Sokoto, Nigeria. Sci Res Essays 2012, 7(3):410418.

5. Adinma B, Echendu D: Perceptions and practices on menstruation amongst Nigerian secondary school girls.Afr J Reprod Health 2008, 12(1):74-83.

6. oche $\mathrm{m}$, umar a, gana g, ango j: menstrual health: the unmet needs of adolescent girls' in sokoto, nigeria. sci res essays 2012, 7(3):410-418

7. s sangeetha balamurugan, a community based study on menstrual hygiene among reproductive age group year:2014,volume 3; issue 2:83-87

8. UZOCHUKWUUZOMAANIEBUE ET AL,THE IMPACT OF PRE-MENARCHEAL TRAINING ON MENSTRUAL PRACTICES AND HYGIENE OF NIGERIAN SCHOOL GIRLS; THE PAN AFRICAN MEDICAL JOURNAL. 2009;2:9. OI:10.11604/PAMJ.2009.2.9.48

9. nair $p$, grover vl, kannan a t. awareness and practices of menstruation and pubertal changes amongst unmarried female adolescents in a rural area of east delhi. indian j community med $\begin{array}{lllllllllllll}2 & 0 & 0 & 7 & ; & 3 & 2 & : & 1 & 5 & 6 & - & 7\end{array}$ 10.ahuja a, tewari s. awareness of pubertal changes among adolescent girls. j fam welfare 1995;41:46-50

11. echendu dolly adinma, j.i.b. adinma, perceptions and practices on menstruation amongst nigerian secondary school girls african journal of reproductive health vol. 12 no. 1 april, 2008

12. çevirme et al,the perception of menarche and menstruation among turkish married women;social behavior and personality: an international journal, volume 38 , number 3 , 2010, pp. 381-393(13)

13. syedanaghmarizvi, menstrual knowledge and 
practices of female adolescents in urban karachi, pakistan, journal of adolescence; volume 33;issue 4:year 2010; page 531-541

14. pragya sharma et al, problems related to menstruation amongst adolescent girls; the indian journal of pediatrics; february 2008 , volume 75, issue2, pp 125-129

15. desalegn tegabu zegeye et al, age at menarche and the menstrual pattern of secondary school adolescents in northwest ethiopia;bmc women's health 20099:29: 5 october 2009

16. rajanibalajasrotia et al, knowledge, attitude and practices of indian girls on various aspects of menstruation; transworld medical journal issn: 23472790 